\title{
Gastroprotective effects of arctigenin of Arctium lappa L. on a rat model of gastric ulcers
}

\author{
XIAO-MEI LI, YU MIAO, QIN-YONG SU, JING-CHUN YAO, HONG-HUA LI and GUI-MIN ZHANG \\ Lunan Pharmaceutical Group Co., Ltd., State Key Laboratory of Generic Manufacture \\ Technology of Chinese Traditional Medicine, Linyi, Shandong 276006, P.R. China
}

Received April 4, 2016; Accepted July 12, 2016

DOI: $10.3892 / \mathrm{br} .2016 .770$

\begin{abstract}
In the present study, the gastroprotective effects of arctigenin of Fructus Arctii were evaluated and the possible underlying mechanisms of action were elucidated. Arctigenin (high-performance liquid chromatography purity, >99.0\%) was isolated and purified from the seeds of Arctium lappa L. The anti-ulcerogenic activity of arctigenin against ulcers induced by absolute ethanol and acetic acid was evaluated in a Sprague-Dawley rat model. In addition, the antioxidant activity was assessed by measuring malondialdehyde (MDA) levels in an ethanol-induced model and the anti-inflammatory effects were assessed by measuring five factors in an acetic acid-induced model. In the ethanol-induced model, arctigenin inhibited gastric lesions in a dose-dependent manner, by $53.04,53.91$ and $64.43 \%$ at doses of $0.05,0.15$ and $0.45 \mathrm{mg} / \mathrm{kg}$, respectively. In addition, arctigenin reduced MDA $(\mathrm{P}<0.01)$ and increased superoxide dismutase $(\mathrm{P}<0.01)$ levels in serum when compared with the vehicle group. The lesion index induced by acetic acid was significantly inhibited by all doses of arctigenin $(0.05,0.15$ and $0.45 \mathrm{mg} / \mathrm{kg} ; \mathrm{P}<0.01)$ in comparison to the vehicle group and in a dose-dependent manner. In addition, it was shown that the expression levels of tumor necrosis factor- $\alpha$, interleukin-6 (IL-6), IL-10 and C-reactive protein were significantly decreased $(\mathrm{P}<0.05)$ in the arctigenin group compared with the vehicle group. Thus, the current study indicated that arctigenin exerted anti-ulcer activity, which may be associated with its reduction in oxidative and inflammatory
\end{abstract}

Correspondence to: Dr Jing-Chun Yao, Lunan Pharmaceutical Group Co., Ltd., State Key Laboratory of Generic Manufacture Technology of Chinese Traditional Medicine, 209 Hongqi Road, Linyi, Shandong 276006, P.R. China

E-mail: yaojingchun@yeah.net

Abbreviations: ARG, arctigenin; MDA, malondialdehyde; SOD, superoxide dismutase; TNF- $\alpha$, tumor necrosis factor- $\alpha$; IL-6, interleukin-6; IL-10, interleukin-10; CRP, C-reactive protein

Key words: arctigenin, gastroprotective, inflammation, antioxidant activity damage. All the results indicate that arctigenin may be used as an effective therapeutic agent to prevent gastric ulcers.

\section{Introduction}

Gastric ulcers are characterized by necrosis, induction of oxidative stress and secretion of inflammatory factors (1). In the Western population, the prevalence of gastric ulcers is $2.4 \%$ (2) and $6.07 \%$ in China (3). In addition, in patients with gastrointestinal symptoms, the incidence rates of gastric ulcers increases to $22.5 \%$ (4). According to the epidemiological investigation, when individuals smoke, consume alchol or use nonsteroidal anti-inflammatory drugs, the incidence of gastric ulcer increases (5-7). Although gender differences have not been reported for gastric ulcers, the incidence rate in women has increased during the previous 10 years (8). The pathogenesis of gastric ulcers is based on a multifactorial and complex interaction between protective and aggressive factors, including mucosal integrity, secretion of gastric acid, Helicobacter pylori, free oxygen radicals and excess alcohol consumption (9-11). Currently, the treatment is predominantly performed by inhibition of gastric acid secretion, proton pump inhibitors and eradication of $H$. pylori with antibiotics. However, such treatments are not completely effective and produce certain adverse effects (12). Disturbing the balance between aggressive and protective factors that control cell apoptosis and proliferation results in gastric ulceration, which then activates the repairing system in the gastric mucosa. For these reasons, the search for novel therapeutic agents is relevant, and medicinal plants and natural products are included in these studies, since many extracts and isolated compounds have shown promising results in gastroprotective activities $(13,14)$.

Fructus Arctii, the dried fruits of Arctium lappa L., are well-known detoxifying agents in traditional Chinese medicine (15). Arctigenin is a lignin constituent of Fructus Arctii. Arctigenin displays anti-H. pylori (16) and anti-inflammatory activity (17-19), inhibits $\mathrm{T}$ lymphocyte proliferation and the gene expression of IL- 6 and interferon- $\gamma$, and exerts anti-tumor activity against pancuronium-1 cells $(20,21)$. However, there are few studies analyzing anti-ulcer activity using arctigenin. Therefore, the present study aimed to evaluate the potential effects of arctigenin on the prevention (by the absolute ethanol model of ulcer induction) and the treatment of experimental 
gastric ulcers (by the acetic acid model of ulcer induction). In addition, malondialdehyde (MDA) and superoxide dismutase (SOD) levels in serum and expression levels of cytokines, such as tumor necrosis factor- $\alpha$ (TNF- $\alpha$ ), interleukin-6 (IL-6), IL-10 and C-reactive protein (CRP) in the gastric tissues were evaluated.

In the present study, the preventive effect of arctigenin on gastric ulcers was investigated in a Sprague-Dawley (SD) rat model. The results indicate that arctigenin effectively decreases inflammatory factors in gastric ulcer rats and protects them from gastric ulcer lesions.

\section{Materials and methods}

Preparation of arctigenin. The dried seeds of Arctium lappa L. were bought from Cangshan (February 2012, Shandong, China). Identification of the plants was confirmed by Dr Li Shouxin (senior engineer; State Key Laboratory of Generic Manufacture Technology of Chinese Traditional Medicine, Linyi, China). A voucher specimen (no. 20110920) was deposited in the State Key Laboratory of Generic Manufacture Technology of Chinese Traditional Medicine. The Fructus Arctii was hydrolyzed by acid hydrolysis and alcohol extraction. The crude product was separated by ethyl acetate extraction, and the arctigenin with $>75 \%$ purity was collected. A high purity of arctigenin was obtained by ethanol crystallization. The finished product was crystallized with anhydrous ethanol until the purity of arctigenin was $>99 \%$.

Animals. One hundred male SD rats $(200 \pm 20 \mathrm{~g}$; age, 8-10 weeks) were supplied by Lunan Pharmaceutical Group Co., Ltd. (Linyi, China), acclimatized to a controlled temperature $\left(23 \pm 2^{\circ} \mathrm{C}\right)$ and maintained under a 12-h light/dark cycle. The animals were supplied with pellet chow and water ad libitum. All experiments were in accordance with the experimental protocols previously approved by the Institution Animal Ethics Committee at the Pharmacological Center of Lunan Pharmaceutical Group Co., Ltd., and performed in accordance with the Declaration of Helsinki.

Ethanol-induced gastric ulcer. The model of ethanol-induced ulcers was performed as described previously with minor modifications (22). Rats were randomly divided into five groups ( $n=8$ per group). Animals were administrated with vehicle [20\% PEG400 (Shanghai Chemical Co., Shanghai, China) in saline], graded doses of arctigenin $(0.05,0.15$ and $0.45 \mathrm{mg} / \mathrm{kg}$; purity, $>99 \%$, extracted in our laboratory) dissolved in saline containing 20\% PEG400 or cimetidine $(36 \mathrm{mg} / \mathrm{kg}$; Shandong Fangming Pharmaceutical Group Co., Ltd., Heze, China) for 6 days. Animals were deprived of food for $24 \mathrm{~h}$ before experiments. One-hour post administration with $1 \mathrm{ml}$ absolute ethanol, animals were anesthetized with pentobarbital (50 mg/kg; Sigma-Aldrich, St. Louis, MO, USA), the inferior vena cava was punctured and 2-ml blood samples were collected in pro-coagulation tubes to obtain the serum (by centrifugation at $1,024 \mathrm{x}$ g for $10 \mathrm{~min}$ at $4^{\circ} \mathrm{C}$ ). The serum was stored at $-80^{\circ} \mathrm{C}$. The rats were anesthetized with $3 \%$ pentobarbital (Sigma-Aldrich) the abdomen was opened, to expose the abdominal aorta, and the rats were sacrificed by bloodletting of the vena cardinalis. The stomachs were removed on ice, opened along the greater curvature, washed with saline $(0.9 \%)$, and the ulcer index was evaluated according to the number and severity of lesions formed. The scoring was performed according to the following scale (23): 0, no visible ulcers; 1, petechial hemorrhage or minute pin-point ulcers; 2 , striate hemorrhage and erosion $<2 \mathrm{~mm} ; 3$, striate hemorrhage and erosion $\geq 2$ and $<3 \mathrm{~mm} ; 4$, striate hemorrhage and erosion $\geq 3$ and $<4 \mathrm{~mm} ; 5$, striate hemorrhage and erosion $\geq 4$ and $<5 \mathrm{~mm}$.

The mean ulcer indices in each group were calculated and expressed as the percentage of inhibition using the following formula: Inhibition $(\%)=($ control mean - treated mean $/$ control mean) x 100 .

Acetic acid-induced gastric ulcer. The experiment was performed as described previously (24) with minor modifications. Rats had been fasting for $12 \mathrm{~h}$ before the experiment and had free access to water. A longitudinal incision below the xiphoid process was made in the anesthetized rats. The anterior wall of the stomach was exposed, then $0.02 \mathrm{ml}$ of $30 \%$ acetic acid was injected with a microsyringe in the subserosal layer at the junction of the fundus with the antrum, and later washed with saline. On the following day, the daily treatments were initiated (once a day for 12 days) in six groups: sham, vehicle, cimetidine $(36 \mathrm{mg} / \mathrm{kg})$, arctigenin $(0.05$, 0.15 and $0.45 \mathrm{mg} / \mathrm{kg}$ ) and the sham group (that underwent the surgical procedure of ulcer induction without the application of acetic acid). Following the final treatment, the rats were anesthetized with $3 \%$ pentobarbital and sacrificed as described above. The stomachs were removed. The minimum and maximum diameters of the open ulcer were then measured, and the product was considered to be the ulcer index. The 100 -mg gastric tissue samples obtained from the corpus region were stored at $-80^{\circ} \mathrm{C}$ for the subsequent measurement of TNF- $\alpha$, IL-6, IL-10 and CRP using ELISA.

Determination of MDA and SOD serum levels. The blood samples were centrifuged at $1,024 \mathrm{xg}$ for $10 \mathrm{~min}$ at $4^{\circ} \mathrm{C}$ to obtain the serum. Serum levels of MDA and SOD were determined using a MDA Assay kit (Nanjing JianCheng Bioengineering Institute, Nanjing, China) and Total SOD Assay kit (Nanjing JianCheng Bioengineering Institute) according to the manufacturer's instructions.

Measurement of TNF- $\alpha, I L-6, I L-10$ and CRP expression levels. Tissue samples were homogenized in 10 volumes of $0.9 \%$ saline and centrifuged at $1,024 \mathrm{x} \mathrm{g}$ at $4^{\circ} \mathrm{C}$ for $15 \mathrm{~min}$. The supernatant was collected and the levels of TNF- $\alpha$ (Tumor Necrosis Factor- $\alpha$ Assay kit; Nanjing JianCheng Bioengineering Institute), IL-6 (Interleukin-6 Assay kit; Nanjing JianCheng Bioengineering Institute), IL-10 (Interleukin-10 Assay kit; Nanjing JianCheng Bioengineering Institute) and CRP (C-Reactive Protein Assay kit; Nanjing JianCheng Bioengineering Institute) were determined by ELISA. All procedures were performed according to the manufacturer's instructions.

Statistical analysis. The parameters were recorded for individuals within all of the groups. Data are presented as the mean \pm standard error of the mean. Statistical analysis was 

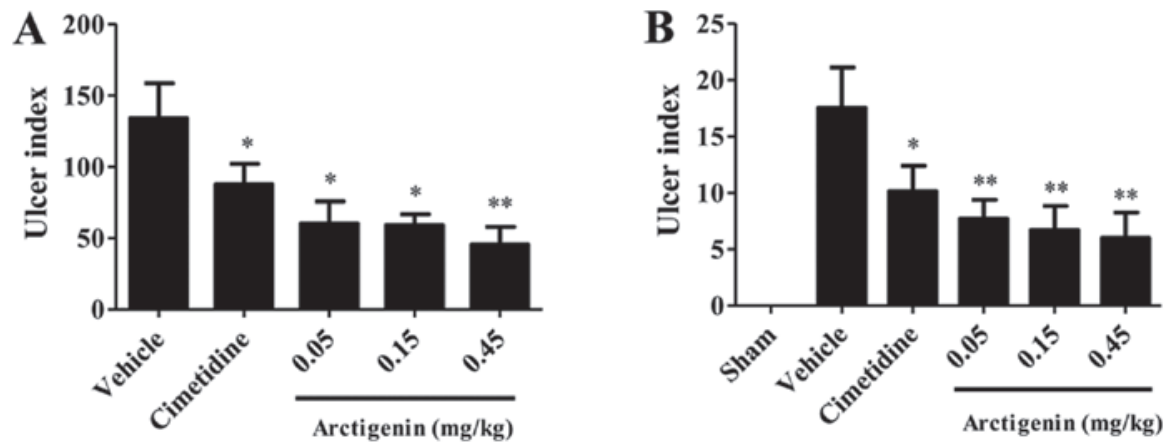

Figure 1. Protective effects of arctigenin on gastric lesions induced by (A) ethanol and (B) acetic-acid in Sprague-Dawley rats. The ulcer index (n=8 per group) is expressed as the mean \pm standard error of the mean (one-way analysis of variance, followed by the least significant difference test). ${ }^{*} \mathrm{P}<0.05$ and ${ }^{* * *} \mathrm{P}<0.01$ vs. vehicle group.

performed with a one-way analysis of variance (ANOVA) using SPSS 17.0 (SPSS, Inc., Chicago, IL, USA) and $\mathrm{P}<0.05$ was considered to indicate a statistically significant difference. Continuous variables are expressed as means \pm standard deviation and compared with two-tailed probability values from an overall $\mathrm{F}$ test from a one-way ANOVA, and pairwise comparisons with Fisher's test of least significant difference.

\section{Results}

Ethanol-induced gastric ulcers. The gastroprotective effects of arctigenin on acetic-induced gastric damage were observed in arctigenin-treated rats (Fig. 1A). Ulcerated rats pretreated with cimetidine or arctigenin demonstrated significantly reduced $(\mathrm{P}<0.05)$ ulcer indices when compared with the vehicle group. The cimetidine and arctigenin at doses of $0.05,0.15$, $0.45 \mathrm{mg} / \mathrm{kg}$ significantly inhibited the appearance of lesions by $31.60,64.43,53.91$ and 53.04\%, respectively. By determination of the ulcer index, arctigenin resulted in an inverted curve, thus, the optimum gastroprotective effect was obtained at a dose of $0.45 \mathrm{mg} / \mathrm{kg}$; Fig. 1A).

Acetic acid-induced chronic ulcer. Serosal application of acetic acid to the vehicle-treated rats resulted in extensive gastric lesions at 10 days of ulcer induction $\left(17.56 \pm 3.56 \mathrm{~mm}^{2}\right)$, where the ulcer erosion index was found to be significantly high when compared with the sham group rats without any lesions $(\mathrm{P}<0.001)$. All doses of arctigenin $(0.05$, 0.15 and $0.45 \mathrm{mg} / \mathrm{kg}$ ) reduced the ulcer index significantly $(\mathrm{P}<0.01)$. However, $36 \mathrm{mg} / \mathrm{kg}$ cimetidine reduced the ulcer index significantly $(\mathrm{P}<0.05)$. The percentages inhibition was $65.83,61.73,56.09$ and $42.14 \%$ for the groups treated with $0.05,0.15$ and $0.45 \mathrm{mg} / \mathrm{kg}$ and cimetidine, respectively. In the present study, arctigenin also presented an inverted curve, so that the best gastroprotective effect was obtained at a dose of $0.45 \mathrm{mg} / \mathrm{kg}$; Fig. 1B).

Determination of the sera levels of MDA and SOD. For the group that received vehicle only, the level of MDA was $7.963 \pm 0.680 \mathrm{nmol} / 1$. Pretreatment with arctigenin at doses of $0.05,0.15,0.45 \mathrm{mg} / \mathrm{kg}$ and cimetidine significantly decreased the levels of MDA $(5.670 \pm 0.264,4.962 \pm 0.311,4.979 \pm 0.260$ and $5.527 \pm 0.231 \mathrm{nmol} / 1$, respectively) compared with the vehicle group $(\mathrm{P}<0.01$; Fig. $2 \mathrm{~A})$. The SOD level in arctigenin-treated at
$0.05 \mathrm{mg} / \mathrm{kg}(122.39 \pm 6.85 \mathrm{U} / \mathrm{ml}), 0.15 \mathrm{mg} / \mathrm{kg}(119.33 \pm 4.04 \mathrm{U} / \mathrm{ml})$ and $0.45 \mathrm{mg} / \mathrm{kg}(145.50 \pm 6.83 \mathrm{U} / \mathrm{ml})$ significantly increased the SOD level compared with the vehicle group $(124.28 \pm 6.27 \mathrm{U} / \mathrm{ml})$ ( $\mathrm{P}<0.05$; Fig. 2B).

Comparison of the levels of cytokines in rat stomach tissue samples. All doses of arctigenin treatment significantly reduced the TNF- $\alpha$ levels $(364.55 \pm 27.22,348.43 \pm 41.45$ and $355.13 \pm 60.35 \mathrm{ng} / \mathrm{l} ; \mathrm{P}<0.01)$ when compared with the vehicle group $(534.17 \pm 49.91 \mathrm{ng} / \mathrm{l})$. However, treatment of cimetidine at the doses of $36 \mathrm{mg} / \mathrm{kg}$ did not significantly decrease the TNF- $\alpha$ levels (Fig. 3A).

The IL-10 levels in the vehicle group increased significantly $(692.21 \pm 27.36 \mathrm{pg} / \mathrm{l} ; \mathrm{P}<0.01)$ compared with the sham group $(605.75 \pm 57.20 \mathrm{pg} / \mathrm{l}$; Fig. 3B). The rats that received $0.05,0.15$ and $0.45 \mathrm{mg} / \mathrm{kg}$ arctigenin demonstrated significantly reduced IL-10 levels $(612.49 \pm 40.39,473.02 \pm 36.30$ and $489.46 \pm 36.26 \mathrm{pg} / \mathrm{l}$, respectively; $\mathrm{P}<0.001)$ when compared with the vehicle group. The other groups were not significantly altered compared with the vehicle group.

Treatment with arctigenin at doses of 0.05 , 0.15 and $0.45 \mathrm{mg} / \mathrm{kg}$ significantly decreased the levels of CRP $[2.75 \pm 0.19 \mu \mathrm{g} / \mathrm{l}(\mathrm{P}<0.05) ; 1.79 \pm 0.18 \mu \mathrm{g} / 1 \quad(\mathrm{P}<0.01)$ and $1.38 \pm 0.08 \mu \mathrm{g} / 1(\mathrm{P}<0.01)$, respectively] when compared with the vehicle group. However, rats that received cimetidine showed no significant reduction in the CRP level when compared with the vehicle group (2.98 $\pm 0.24 \mu \mathrm{g} / \mathrm{l} ; \mathrm{P}>0.05)$ (Fig. 3C).

The gastric tissue IL-6 level in the vehicle group (32.97 $\pm 5.30 \mathrm{ng} / \mathrm{l})$ demonstrated a significant increase when compared with the sham group $(20.48 \pm 1.05 \mathrm{ng} / \mathrm{l} ; \mathrm{P}<0.05)$. However, cimetidine showed no significant reduction in the IL-6 level when compared with the vehicle group. In addition, $0.05,0.15$ and $0.45 \mathrm{mg} / \mathrm{kg}$ arctigenin exhibited strong inhibition effects on IL-6 $(23.77 \pm 2.88,21.20 \pm 2.94$ and $15.68 \pm 1.17 \mathrm{ng} / \mathrm{l})$ compared with vehicle group (Fig. 3D).

\section{Discussion}

To the best of our knowledge, the present study is the first to report the gastroprotective of arctigenin from Fructus Arctii, which inhibits the ulcer index induced by absolute ethanol and acetic acid (Fig. 1), and provides experimental evidence to support the traditional use of Fructus Arctii in the treatment of stomach dysfunction. 

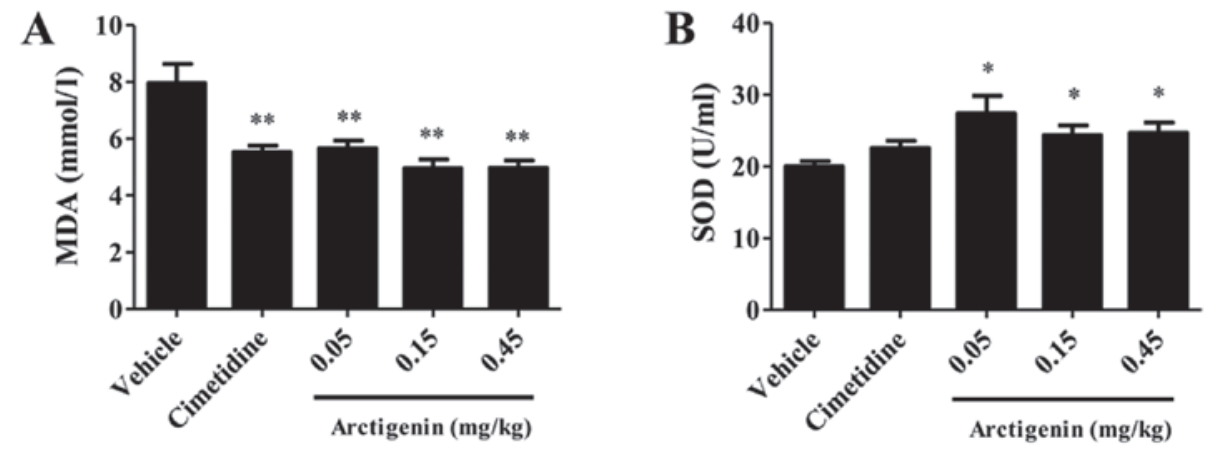

Figure 2. Effects of pretreatment with arctigenin on the serum (A) MDA and (B) SOD levels in rats that received absolute ethanol. The results are expressed as means \pm standard error of the mean ( $n=8$; one-way analysis of variance, followed by the least significant difference test). ${ }^{*} \mathrm{P}<0.05$ and ${ }^{* *} \mathrm{P}<0.01$ vs. vehicle group. MDA, malondialdehyde; SOD, superoxide dismutase.

$\mathbf{A}$

C
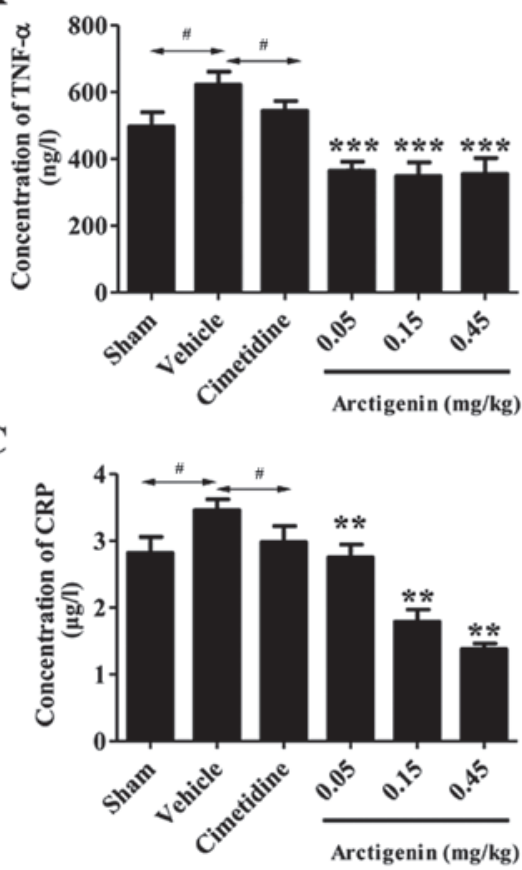

B

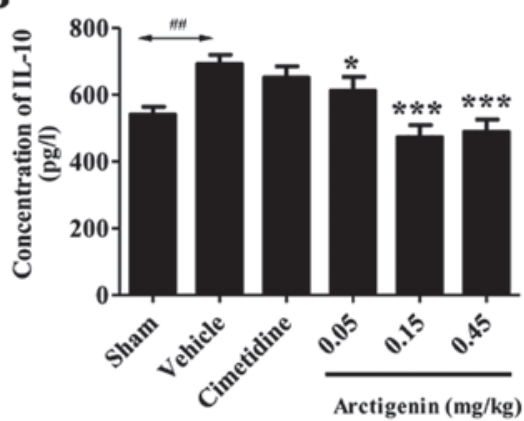

D

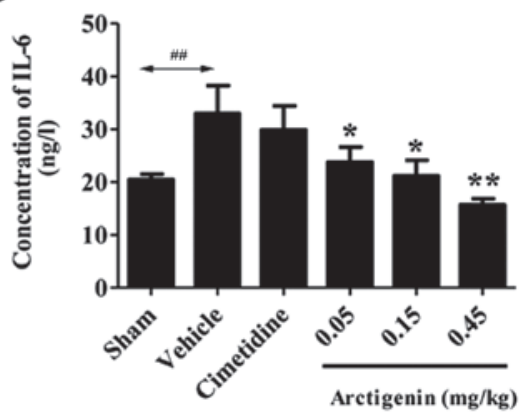

Figure 3. Effects of arctigenin on the (A) TNF- $\alpha$, (B) IL-10, (C) CRP and (D) IL-6 level in acetic acid-induced chronic ulcer. The results are expressed as means \pm standard error of the mean $\left(\mathrm{n}=10\right.$; one-way analysis of variance, followed by the least significant difference test). ${ }^{*} \mathrm{P}<0.05,{ }^{* * *} \mathrm{P}<0.01$ and ${ }^{* * * *} \mathrm{P}<0.001$ vs. vehicle group; ${ }^{\#} \mathrm{P}<0.05 ;{ }^{\# /} \mathrm{P}<0.01$. TNF- $\alpha$, tumor necrosis factor- $\alpha$; IL, interleukin; CRP, C-reactive protein.

Ethanol and acetic acid are the most commonly utilized experimental models for the evaluation of anti-ulcer activity in rats $(24,25)$. The gastroprotective effect of arctigenin in different experimental ulcer models is presented in the current study, as various mechanisms are involved in the etiology of gastric ulcers. Ethanol-induced gastric ulcers are a reliable model of acute gastric mucosal ulceration; as shown in Fig. 1A, arctigenin treatment inhibited the gastric damage induced by ethanol at all doses with similar efficacy as compared with the vehicle group.

In addition to the gastroprotective effect of arctigenin, the healing effect on the gastric mucosa in the acetic acid-induced ulcer model was investigated. This chronic ulcer model, which highly resembles human chronic ulcers in terms of pathological features and healing mechanisms, is utilized to develop novel anti-ulcer medication, which may potentially prevent ulcer relapse or enhance ulcer healing (26). Acetic acid is reported to produce ulcers by gastric obstruction leading to increased quantities of acidic gastric juice $(27,28)$. In the current study, arctigenin caused significant reductions in gastric lesions at all doses tested, when compared with the vehicle group (Fig. 1B), indicating that arctigenin exerted curative effects. This result suggested that arctigenin may have protective effects in the treatment of chronic ulcers.

The effects of ethanol on the gastric mucosa may be associated with the formation of reactive oxygen species (ROS), which cause an imbalance between oxidant and antioxidant cellular processes. It is known that lipid peroxidation is the result of ROS interacting with the cell membrane, subsequently producing highly reactive lipid-derived free radicals, such as MDA, to cause oxidative gastric damage (29). However, organisms possess enzymatic defenses (SOD) against the lipid peroxidation. In the current study, arctigenin lowered the elevated MDA level and increased the SOD level (Fig. 2). Thus, 
it was concluded that the ability of arctigenin to reduce the MDA level and increase the SOD level may contribute to its gastroprotective effect by inhibiting oxidative gastric damage.

Inflammation is generally considered to be a highly regulated defensive process characterized by the release of cytokines from the blood to the affected tissue (30). The potent pro-inflammatory cytokines (such as TNF, IL-1, interferon- $\gamma$ ) are involved in the occurrence and development of inflammatory responses $(31,32)$. The acetic acid, a well-known ulcerogenic agent, stimulates inflammation via the imbalance of pro- and anti-inflammatory cytokines (33). In the current study, acetic acid-induced ulcer models were used to investigate the gastroprotective effect of arctigenin. Arctigenin effectively regulated four pro-inflammatory cytokines and attenuated acetic acid-induced ulcers. Thus, in the present study TNF- $\alpha$, IL-6, IL-10 and CRP were evaluated in gastric homogenate (Fig. 3). TNF- $\alpha$, which is increased in non-steroidal anti-inflammatory drug-treated rats, appears to be a key contributor on many forms of gastric mucosal damage $(34,35)$. IL-10 is a pleiotropic cytokine with important immunoregulatory functions whose actions influence activities of many cell-types in the immune system. The levels of IL-10 are prominently increased in peptic ulcer patients (36). Numerous clinical studies reported that the levels of inflammatory factors (IL-6, CRP and TNF- $\alpha$ ) were consistent with the pathogenic condition of gastric ulcer patients (37). It is reported that an elevated CRP level is a positive predictive value for peptic ulcers caused by active inflammation (38). These results corroborated the report of Hyam et al (39), who observed that arctigenin inhibited 2,4,6-trinitrobenzenesulfonic acid-induced IL- 6 and TNF- $\alpha$ expression. These findings reveal that the anti-ulcerogenic effects of arctigenin may be mediated by anti-inflammatory activities.

The results of the present study indicate that arctigenin afforded remarkable ameliorative effects against gastric mucosal lesions induced by ethanol and acetic acid, thereby confirming anti-ulcer activity in SD rats. The gastroprotective effect of arctigenin may be attributed to its activities against oxidative and inflammatory damage. In conclusion, the results obtained in the present study provide support for the use of arctigenin as a gastroprotective medicine. Furthermore, the current study provides more information on the possible underlying mechanisms by which arctigenin exerts its anti-ulcer effects.

\section{Acknowledgements}

The present study was supported by the National Science and Technology Support Program (grant no. 2012CB724001) and the Shandong province Science and Technology Major Project (grant no. 2015ZDJQ05004), gratefully received from The Generic Manufacture Technology of Chinese Traditional Medicine and Lunan Pharmaceutical Group Co., Ltd.

\section{References}

1. de Souza Almeida ES, Filho VC, Niero R, Clasen BK, Balogun SO and de Oliveira Martins DT: Pharmacological mechanisms underlying the anti-ulcer activity of methanol extract and canthin-6-one of Simaba ferruginea A. St-Hil. in animal models. J Ethnopharmacol 134: 630-636, 2011.
2. Groenen MJ, Kuipers EJ, Hansen BE and Ouwendijk RJ: Incidence of duodenal ulcers and gastric ulcers in a Western population: Back to where it started. Can J Gastroenterol 23: 604-608, 2009.

3. Dong WG, Cheng CS, Liu SP and Yu JP: Epidemiology of peptic ulcer disease in Wuhan area of China from 1997 to 2002. World J Gastroenterol 10: 3377-3379, 2004

4. Li Z, Zou D, Ma X, Chen J, Shi X, Gong Y, Man X, Gao L, Zhao Y, Wang R, et al: Epidemiology of peptic ulcer disease: Endoscopic results of the systematic investigation of gastrointestinal disease in China. Am J Gastroenterol 105: 2570-2577, 2010.

5. Maity P, Biswas K, Roy S, Banerjee RK and Bandyopadhyay U: Smoking and the pathogenesis of gastroduodenal ulcer - recent mechanistic update. Mol Cell Biochem 253: 329-338, 2003.

6. García Rodríguez LA and Hernández-Díaz S: Risk of uncomplicated peptic ulcer among users of aspirin and nonaspirin nonsteroidal antiinflammatory drugs. Am J Epidemiol 159: 23-31, 2004.

7. Ko JK and Cho CH: Alcohol drinking and cigarette smoking: A 'partner' for gastric ulceration. Zhonghua Yi Xue Za Zhi (Taipei) 63: 845-854, 2000.

8. Wysocki A, Budzyński P, Kulawik J and Drożdż W: Changes in the localization of perforated peptic ulcer and its relation to gender and age of the patients throughout the last 45 years. World J Surg 35: 811-816, 2011.

9. Bhattacharya S, Banerjee D, Bauri AK, Chattopadhyay S and Bandyopadhyay SK: Healing property of the Piper betel phenol, allylpyrocatechol against indomethacin-induced stomach ulceration and mechanism of action. World J Gastroenterol 13: 3705-3713, 2007.

10. Pakrashi A, Pandit S, Bandyopadhyay SK and Pakrashi SC: Antioxidant effect of Phyllanthus emblica fruits on healing of indomethacin induced gastric ulcer in rats. Indian J Clin Biochem 18: 15-21, 2003.

11. Zheng XG, Zhang JJ and Huang YC: Study on the effect of weitongning on epidermal growth factor and nitric oxide contents in tissue of stomach of rats with gastric ulcer. Zhongguo Zhong Xi Yi Jie He Za Zhi 24: 549-551, 2004 (In Chinese).

12. Lin PC, Chang CH, Hsu PI, Tseng PL and Huang YB: The efficacy and safety of proton pump inhibitors vs histamine-2 receptor antagonists for stress ulcer bleeding prophylaxis among critical care patients: A meta-analysis. Crit Care Med 38: 1197-1205, 2010

13. Vasconcelos PC, Andreo MA, Vilegas W, Hiruma-Lima CA and Pellizzon CH: Effect of Mouriri pusa tannins and flavonoids on prevention and treatment against experimental gastric ulcer. J Ethnopharmacol 131: 146-153, 2010.

14. Karakoyun B, Yüksel M, Ercan F, Erzik C and Yeğen BC: Alpha-lipoic acid improves acetic acid-induced gastric ulcer healing in rats. Inflammation 32: 37-46, 2009.

15. Park SY, Hong SS, Han XH, Hwang JS, Lee D, Ro JS and Hwang BY: Lignans from Arctium lappa and their inhibition of LPS-induced nitric oxide production. Chem Pharm Bull (Tokyo) 55: 150-152, 2007.

16. Kamkaen N, Matsuki Y, Ichino C, Kiyohara H and Yamada H: The isolation of the anti-helicobacter pylori compoundsin seeds of Arctium lappa Linn. Thai Pharm Health Sci J 1: 12-18, 2006.

17. Kang HS, Lee JY and Kim CJ: Anti-inflammatory activity of arctigenin from Forsythiae Fructus. J Ethnopharmacol 116: 305-312, 2008

18. Kou X, Qi S, Dai W, Luo L and Yin Z: Arctigenin inhibits lipopolysaccharide-induced iNOS expression in RAW264.7 cells through suppressing JAK-STAT signal pathway. Int Immunopharmacol 11: 1095-1102, 2011.

19. Zhao F, Wang L and Liu K: In vitro anti-inflammatory effects of arctigenin, a lignan from Arctium lappa L., through inhibition on iNOS pathway. J Ethnopharmacol 122: 457-462, 2009.

20. Tsai WJ, Chang CT, Wang GJ, Lee TH, Chang SF, Lu SC and Kuo YC: Arctigenin from Arctium lappa inhibits interleukin-2 and interferon gene expression in primary human $\mathrm{T}$ lymphocytes. Chin Med 6: 12, 2011.

21. Awale S, Lu J, Kalauni SK, Kurashima Y, Tezuka Y, Kadota S and Esumi H: Identification of arctigenin as an antitumor agent having the ability to eliminate the tolerance of cancer cells to nutrient starvation. Cancer Res 66: 1751-1757, 2006.

22. Morimoto Y, Shimohara K, Oshima S and Sukamoto T: Effects of the new anti-ulcer agent KB-5492 on experimental gastric mucosal lesions and gastric mucosal defensive factors, as compared to those of teprenone and cimetidine. Jpn J Pharmacol 57: 495-505, 1991 
23. Guth PH, Aures D and Paulsen G: Topical asprin plus $\mathrm{HCl}$ gastric lesions in the rats. Cytoprotective effect of prostaglandin, cimetidine, and probanthine. Gastroenterology 76: 88-93, 1979.

24. Okabe S and Amagase K: An overview of acetic acid ulcer models - the history and state of the art of peptic ulcer research. Biol Pharm Bull 28: 1321-1341, 2005.

25. Mutoh H, Hiraishi H, Ota S, Ivey KJ, Terano A and Sugimoto T: Role of oxygen radicals in ethanol-induced damage to cultured gastric mucosal cells. Am J Physiol 258: G603-G609, 1990.

26. Jung J, Bae KH and Jeong CS: Anti-Helicobacter pylori and antiulcerogenic activities of the root cortex of Paeonia suffruticosa. Biol Pharm Bull 36: 1535-1539, 2013.

27. Zhang FY, Yang FJ, Yang JL, Wang L and Zhang Y: Renin inhibition improves ovariectomy-induced osteoporosis of lumbar vertebra in mice. Biol Pharm Bull 37: 1994-1997, 2014.

28. Jainu M and Devi CS: Antiulcerogenic and ulcer healing effects of Solanum nigrum (L.) on experimental ulcer models: Possible mechanism for the inhibition of acid formation. J Ethnopharmacol 104: 156-163, 2006.

29. Kwiecień S, Brzozowski T and Konturek SJ: Effects of reactive oxygen species action on gastric mucosa in various models of mucosal injury. J Physiol Pharmacol 53: 39-50, 2002.

30. Bradding P, Feather IH, Wilson S, Bardin PG, Heusser CH, Holgate ST and Howarth PH: Immunolocalization of cytokines in the nasal mucosa of normal and perennial rhinitic subjects. The mast cell as a source of IL-4, IL-5, and IL-6 in human allergic mucosal inflammation. J Immunol 151: 3853-3865, 1993

31. Su SC, Hua KF, Lee H, Chao LK, Tan SK, Lee H, Yang SF and Hsu HY: LTA and LPS mediated activation of protein kinases in the regulation of inflammatory cytokines expression in macrophages. Clin Chim Acta 374: 106-115, 2006.
32. Wang HD, Lu DX and Qi RB: Therapeutic strategies targeting the LPS signaling and cytokines. Pathophysiology 16: 291-296, 2009.

33. Beserra AM, Calegari PI, Souza MC, Dos Santos RA, Lima JC, Silva RM, Balogun SO and Martins DT: Gastroprotective and ulcer-healing mechanisms of ellagic acid in experimental rats. J Agric Food Chem 59: 6957-6965, 2011.

34. Martin GR and Wallace JL: Gastrointestinal inflammation: A central component of mucosal defense and repair. Exp Biol Med (Maywood) 231: 130-137, 2006.

35. Appleyard CB, McCafferty DM, Tigley AW, Swain MG and Wallace JL: Tumor necrosis factor mediation of NSAID-induced gastric damage: Role of leukocyte adherence. Am J Physiol 270: G42-G48, 1996.

36. Li TT and Liu XH: Clinical value of determination of changes of serum Gas, IL-2, IL-10 and IL-18 levels after transfusion of Red blood cells in patients with peptic ulcer. Journal of Radioimmunology 24: 515-517, 2011.

37. Zhang Y: Impact of esomeprazole on gastrointestinal hormones and inflammatory state of patients with gastric ulcer. Journal of Clinical Medicine in Practice 17: 68-70, 2013.

38. Boehme MW, Autschbach F, Ell C and Raeth U: Prevalence of silent gastric ulcer, erosions or severe acute gastritis in patients with type 2 diabetes mellitus - a cross-sectional study. Hepatogastroenterology 54: 643-648, 2007.

39. Hyam SR, Lee IA, Gu W, Kim KA, Jeong JJ, Jang SE, Han MJ and Kim DH: Arctigenin ameliorates inflammation in vitro and in vivo by inhibiting the PI3K/AKT pathway and polarizing M1 macrophages to M2-like macrophages. Eur J Pharmacol 708: $21-29,2013$ 